\title{
Interactive comment on "Implementation of WRF-Hydro at two drainage basins in the region of Attica, Greece” by Elissavet Galanaki et al.
}

\section{Elissavet Galanaki et al.}

galanaki@noa.gr

Received and published: 7 December 2020

The comment was uploaded in the form of a supplement:

https://nhess.copernicus.org/preprints/nhess-2020-26/nhess-2020-26-AC2-

supplement.pdf

Interactive comment on Nat. Hazards Earth Syst. Sci. Discuss., https://doi.org/10.5194/nhess2020-26, 2020. 